\title{
Proceso Arbitral e Interpretación Prejudicial de Normas Comunitarias Andinas
}

\author{
Sasha Mandakovic Falconi
}

\begin{abstract}
Sumario
1. El Acuerdo de Cartagena y la normativa andina. 2. El Tribunal de Justicia de la Comunidad Andina y la denominada "interpretación prejudicial". 3. La interpretación prejudicial en procesos arbitrales: sentencia emitida en el proceso de acción de incumplimiento No. 03-AI-2010. 4. Consecuencias de la falta de Interpretación Prejudicial. 5. El Consejo de Estado de Colombia y cómo reaccionó frente a lo dispuesto en la acción de incumplimiento No. 03-AI-2010 6. Conclusiones.
\end{abstract}

\section{El Acuerdo de Cartagena $Y$}

\section{LA NORMATIVA ANDINA}

El 26 de mayo de 1969 se suscribió el "Acuerdo de Cartagena" entre Bolivia, Colombia, Chile, Ecuador y Perú ${ }^{1}$, el cual a través de los años ha ido evolucionando hasta convertirse en un instrumento internacional cuyo objetivo es promover el desarrollo equilibrado y armónico de los países miembros mediante su integración y cooperación en los ámbitos económico y social. En la Comunidad Andina ("CAN") se busca, a través de la integración, acelerar el crecimiento y progreso económico y social de los países, disminuir las diferencias de desarrollo entre ellos, mejorar

1. En 1973 Venezuela se adhirió al Acuerdo y se separó en el 2006. Por su parte, Chile se retiró en octubre de 1976. 
su posición en el contexto económico internacional y así incrementar, finalmente, el nivel de vida de sus habitantes ${ }^{2}$.

Para alcanzar los objetivos antes señalados, el mismo Acuerdo prevé el uso de una serie de mecanismos y medidas, entre los cuales se encuentran la ejecución de programas industriales coordinados, un programa de liberación de intercambio comercial, fijación de un arancel externo común, y, para efectos del tema que nos compete, "La armonización gradtual de políticas económicas y sociales y la aproximación de las legislaciones nacionales en las materins pertinentes" 3 .

Adicionalmente, el denominado "Sistema Andino de Integración (SAI)", esto es el sistema que adopta la Comunidad Andina para avanzar en sus objetivos, está conformado por una serie de órganos e instituciones, entre ellos el Consejo Andino de Ministros Exteriores, la Comisión de la Comunidad Andina, la Secretaría de la Comunidad Andina, el Tribunal de Justicia de la Comunidad Andina ("TJCA"), y la Corporación Andina de Fomento 4 .

Tanto el Consejo Andino de Ministros Exteriores como la Comisión de la Comunidad Andina, esta última conformada por representantes plenipotenciarios de los gobiernos de los países miembros, tienen facultades normativas a través de la expedición de las llamadas "decisiones". En ejercicio de dichas facultades, se han dictado una serie de decisiones en materias como por ejemplo la aduanera, comercio de bienes y servicios, protección y promoción de la libre competencia, régimen eléctrico, propiedad intelectual y telecomunicaciones.

Las normas que conforman las decisiones son aplicables de manera directa en los países miembros de la CAN a partir de su publicación en la Gaceta Oficial del Acuerdo, a menos que en ellas

2. Acuerdo de Integración Subregional Andino (Acuerdo de Cartagena). Decisión 563 del 26 de junio de 2003.

3. Ibid, Art. 3, lit. b).

4. Ibid, Art. 6. 
se señale una fecha posterior de aplicación o que la misma decisión requiera de su incorporación al derecho interno del país miembro a través de un acto expreso ${ }^{5}$.

Lo anterior se conoce como la aplicación inmediata y el efecto directo de la normativa comunitaria andina, de lo cual además es consecuencia la preeminencia del ordenamiento jurídico comunitario sobre el ordenamiento jurídico nacional.

Estos conceptos, al igual que otros principios básicos del ordenamiento jurídico comunitario, han sido desarrollados por el Tribunal de Justicia de la Comunidad Andina en los siguientes términos:

"1. Principio de Presunción de Validez de la Norma Comunitaria. Es un desarrollo del llamado "principio de legalidad" en el ámbito comunitario. Por el cual, la norma comunitaria se presume válida, vigente y aplicable mientras no sea declarada su nulidad, derogada, suspendida su aplicación, o declarada inaplicable para un caso particular. En este contexto, la norma comunitaria vigente, válida y aplicable, debe ser de obligatorio cumplimiento por parte de todos los Países Miembros.

2. Principio de Aplicación Inmediata. Por este principio se entiende que la norma comunitaria andina derivada se incorpora al ordenamiento jurídico de los Países Miembros de manera automática, esto es, sin necesidad de ningún proceso de recepción, incorporación, homologación o exequátur...

3. Principio de Efecto Directo. Esto es, que la norma comunitaria andina genera derechos y obligaciones de carácter inmediato en cabeza de los nacionales de los Países Miembros, valga decir, sin necesidad de que existan normas jurídicas internas que los desarrollen o reglamenten. Este principio es de gran importancia porque faculta a los particulares a exigir ante las autoridades de sus Países los derechos otorgados por la norma comunitaria. Se desprende del principio de aplica-

5. Art 3 de la Codificación del Tratado de Creación del Tribunal de Justicia de la Comunidad Andina (Decision 472). 
ción inmediata y de la propia naturaleza del Derecho Comunitario Andino...

4. Principio de Primacía. Este principio establece la relación entre el ordenamiento jurídico comunitario andino y otros sistemas normativos, dentro de los que se incluye el ordenamiento interno de los Países Miembros y las normas internacionales multilaterales, plurilaterales o bilaterales. El Tribunal en reiterada jurisprudencia ha delimitado este principio, estableciendo que en caso de presentarse antinomias entre el Derecho Comunitario Andino y el Derecho Interno de los Países Miembros, prevalece el primero, al igual que al presentarse antinomias entre el Derecho Comunitario y las demás normas de Derecho Internacional...

5. Principio de Autonomía. Este principio es un efecto y un complemento claro del Principio de Primacía. Consagra al ordenamiento jurídico comunitario andino como un "sistema jurídico", es decir, como un todo coherente dotado de unidad, basado en un conjunto de principios y reglas estructurales que se derivan de él mismo, sin soportarlas en ningún otro ordenamiento jurídico. En otras palabras, la validez del ordenamiento jurídico comunitario andino no depende de ningún otro ordenamiento local, nacional o internacional..."6

\section{El Tribunal de Justicia de la Comunidad Andina Y LA DENOMINADA "INTERPRETACIÓN PREJUDICIAL"}

Este órgano de la Comunidad Andina inició su funcionamiento en enero de 1984, esto es unos años después de su creación mediante el tratado que fue suscrito para el efecto por los miembros de la CAN en mayo de 1979. Tiene su sede en Quito.

El objetivo de la creación del TJCA ${ }^{7}$ como órgano de la CAN fue tener una instancia jurisdicciona ${ }^{8}$ que pudiera declarar la legalidad de la normativa comunitaria, dirimir las controversias

6. Interpretación prejudicial del Tribunal de Justicia de la Comunidad Andina No. 115-1P-2009 del 25 de febrero de 2010. 
que de su aplicación surjan y además asegurar su interpretación y aplicación uniforme en todos los países miembros.

Entre las competencias que tiene el TJCA se encuentra el conocimiento de la denominada interpretación prejudicial, que consiste en el pronunciamiento que hace el Tribunal sobre el alcance y sentido de las normas que conforman el ordenamiento jurídico de la Comunidad Andina, a efectos de lograr su aplicación uniforme en cada país miembro'.

El Tribunal no se encuentra facultado para interpretar el contenido y alcance del derecho nacional de cada país miembro ni tampoco los hechos que son materia del proceso ${ }^{10}$, por lo cual la interpretación que realiza de las normas comunitarias sirve al juez nacional para entender su sentido y alcance, y así poder aplicarlas correctamente cuando deba dictar sentencia.

Lo que ocurre procesalmente, para efectos de que se lleve a cabo la interpretación prejudicial, es uno de los dos siguientes supuestos:

- Procesos en los que la sentencia es susceptible de recursos en derecho interno: En estos casos es meramente facultativo para el juez nacional solicitar la interpretación de las normas andinas al Tribunal y el pedido, en el supuesto de que se formule, no suspende el decurso del proceso. Esto es, si el pronunciamiento del TJCA demora más allá del término procesal para dictar sentencia, el juez debe dictarla sin esperar ${ }^{11}$.

7. Resulta sumamente intercsante conocer que hasta cl año 2010 el Tribunal habia conocido ya 1813 procesos de interpretación prejudicial, 116 acciones de incumplimiento en contra de los paises miembros, 50 acciones de nulidad, 9 procesos laborales y 6 recursos por omisión o inactividad de los órganos co. munitarios. Segùn la información disponible en la página web de la Comunidad Andina, se ubica asi el Tribunal como la tereera corte internacional más activa del mundo. Ver.

hup://www.comunidadandisa.org/Seccion aspx?id=29\&tipo=SA\&title tribunal-de-justicia-de-la-comunidad-andina

8. Codificación del Tratado de Creación del Tribunal de Justicia de la Comunidad Andina (Decisión 472), Art. 5.

9. Ibid, Art. 32.

10. Ibid, Art. 34 .

11 Ibid. An. 33. 
- Procesos en los que la sentencia no es susceptible de recursos en derecho interno: En este supuesto, es obligatorio para el juez nacional solicitar la interpretación de las normas al Tribunal -ya sea a petición de parte o de oficio-y además el proceso queda suspendido hasta que el TJCA se pronuncie. Esto es, el juez no debe dictar sentencia sino hasta recibir el pronunciamiento del Tribunal ${ }^{12}$.

De la lectura de las normas correspondientes de la Decisión 472 de la CAN, podría surgir como duda cuál es el alcance del concepto "susceptibilidad de recursos en derecho interno", es decir, si esta frase incluye a todo tipo de recursos (ordinarios y extraordinarios) o inclusive acciones.

Sin embargo, este asunto ya ha sido resuelto por el mismo TJCA a través de sus mismas interpretaciones prejudiciales, las cuales, como ya ha sido explicado, sirven para determinar el alcance y sentido de las normas comunitarias.

Así, en el proceso de interpretación prejudicial No. 149-IP2011 el TJCA indicó:

“... la interpretación obligatoria se debe solicitar en procesos de última instancia ordinaria... Como quiera que los recursos extraordinarios son aquellos que tienen unas causales bien demarcadas, que por regla general tienen un carácter técnico-jurídico, que no actúan como instancia porque no pretende revisar en todos sus extremos la actuación del juez ordinario $\mathrm{y}$, por lo tanto, no están destinados a revisar los hechos del proceso ni a realizar un análisis probatorio, no es en sede de dichos recursos que debe ser obligatoria la solicitud de interpretación prejudicial ya que, si así fuera, se quedarían un gran cúmulo de casos, de asuntos y de cuestiones, sin soporte en una uniforme interpretación de la norma comunitaria andina.

... Para revisar un fallo judicial después de que se agota el trámite ordinario, la mayoría de sistemas jurídicos consagran sistemas extraordinarios como el recurso de casación o de

12. Ibid, Art. 33, 2 do inciso. 
revisión, con las características básicas anteriormente anotadas.

A esta vía extraordinaria acceden pocos asuntos debido a su naturaleza restrictiva y de una gran carga técnico-jurídica; cuando la figura extraordinaria está bien empleada, tiene como efecto inmediato la limitación de su campo de acción. Por esta razón y salvaguardando la validez y eficacia del orden jurídico andino, el Tribunal ha considerado que la obligatoriedad de la interpretación prejudicial debe enraizarse en la única o última instancia ordinaria; el operador jurídico más legitimado para desplegar la interpretación uniforme es el juez de única o última instancia ordinaria, precisamente porque éste concreta definitivamente la litis en la gran mayoría de asuntos. Los recursos extraordinarios son precisamente eso, extraordinarios y excepcionales" (resaltado fuera de texto).

Adicionalmente a lo anterior, a la misma República del Ecuador, a través de la resolución 171 del 17 de diciembre de 1998, la Secretaría General de la Comunidad Andina la declaró incumplidora de las normas que conforman el ordenamiento jurídico comunitario, pues en un recurso de apelación de un proceso verbal sumario seguido en la entonces Sala Quinta de la Corte Superior de Justicia de Guayaquil, ésta se negó a remitir el proceso (pues hubo pedido de parte) a interpretación prejudicial, a pesar de tratarse de última instancia ordinaria.

En la citada resolución, la cual fue posteriormente confirmada por la resolución 210, la Secretaría acogió los criterios de varios tratadistas que a la época habían analizado el tema y sostenían que los recursos a los que se refería el Tratado de Creación del Tribunal dentro del concepto de susceptibilidad de recursos en derecho interno, era a los ordinarios únicamente.

Hoy, sobre el tema, que ha sido analizado en sendas interpretaciones prejudiciales, no cabe duda. 


\section{LA INTERPRETACIÓN PREJUDICIAL EN PROCESOS ARBI- TRALES: SENTENCIA EMITIDA EN EL PROCESO DE ACCIÓN DE INCUMPLIMIENTO No. 03-AI-2010}

La obligación de los jueces de los países miembros de la Comunidad Andina de solicitar al Tribunal su pronunciamiento a través de interpretaciones prejudiciales en procesos de única o última instancia ordinaria no trae ninguna novedad respecto de procesos judiciales, a tal punto que desde la creación del TJCA, éste ha interpretado el alcance de normas comunitarias en aproximadamente 2.000 procesos que han sido conocidos por los jueces y tribunales nacionales de los países miembros.

Sin embargo, el tema cobra relevancia para el mundo del arbitraje a propósito de la resolución emitida por el TJCA en el proceso de acción de incumplimiento ${ }^{13}$ 03-AI-2010 del 26 de agosto de 2011, que fue iniciado por la Empresa de Telecomunicaciones de Bogotá S.A. ESP ("ETB") en contra de la República de Colombia, Sección Tercera del Consejo de Estado.

El antecedente de este proceso de incumplimiento fueron los contratos que la ETB celebró con empresas privadas en Colombia (Comcel, Occel y Celcaribe) en materia de telecomunicaciones, específicamente respecto del acceso, uso e interconexión entre la

13. La acción de incumplimiento es aquella que puede ser iniciada por un pais micmbro de la CAN en contra de otro, o por una persona natural o juridica afectada en sus derechos en contra de un pais miembro, en la que se le imputa haber incumplido con obligaciones emanadas de las normas o convenios que forman parte del ordenamiento juridico comunitario. Se trata de una acción que es conocida en primera instancia por la Secretaria General de ta Comunidad Andina quien debe emitir un dictamen que resuclva sobre si lubo incumplimicnto o no lo hubo.

En caso de que el dietamen declare que ha existido un incumplimiento del pais miembro y la conducta no sca subsanada, se remite el proceso al TJCA. Si el TJCA a su vez confima que hubo un incumplimiento, el pais miembro debe adoptar las medidas que sean necesarias para subsanar lo que corresponda en un plazo no mayor a 90 dias.

La falta de cumplimiento puede llevar a sanciones determinadas por el TJCA para cl país que pueden consistir en la suspensión total o parcial de ventajas del Acuerdo de Cartagena que beneficien al pais o la adopción de otras medidas que se consideren pertinentes.

De otro lado, la sentencia de incumplimiento, para cl caso que la acción laya sido interpuesta por una persona natural o juridica, constituye titulo suficiente para reclamar al jucz nacional la indemnización por daños y perjuicios al Estado.

Para mayor detalle, ver articulos 23 a 31 de la Decisión 472, Codificación del Tratado de Creación del TJCA. 
red de telefonía pública y redes de telefonía móvil celular, en donde se había pactado la solución de controversias por medio de arbitraje.

Se produjeron controversias entre las partes en relación a dichos contratos, se iniciaron los procesos arbitrales del caso y al finalizar los mismos, se emitieron los laudos correspondientes. Hasta allí no hubo nada fuera de lo ordinario.

Sin embargo, ETB interpuso acciones de nulidad de los laudos arbitrales ante el Consejo de Estado en Colombia y recién allí solicitó la suspensión de los procesos y su remisión al TJCA para interpretación prejudicial, pues en el proceso se debían aplicar, a criterio de ETB, normas comunitarias referidas al tema de interconexión.

A pesar del pedido de parte, que de ser concedido debía producir la suspensión de los procesos en tratándose de unos de única instancia ordinaria, el Consejo de Estado de Colombia decide resolver los procesos de anulación, negando así su remisión previa al TJCA para que realice interpretaciones prejudiciales.

ETB entonces decidió iniciar una acción de incumplimiento en contra de la República de Colombia con fundamento en el artículo 23 de la Decisión 472 de la CAN, pues consideró que el país había incurrido en un incumplimiento de obligaciones emanadas de normas del ordenamiento de la Comunidad Andina.

Para estos efectos ETB siguió el procedimiento correspondiente: presentó su acción ante la Secretaría General de la Comunidad Andina quien consideró que la República de Colombia no había incurrido en un incumplimiento, por lo cual ETB reclamó directamente al TJCA, quien terminó por declarar que en efecto había un incumplimiento ${ }^{14}$ de la normativa comunitaria.

14. Nótese que en la resolución de la acción de incumplimiento No. 03-Al-2010 el Tribunal indica que el Consejo de Estado de la República de Colombia no incurrió cn una falla al no solicitar la interpretación prejudicial de normas comunitarias objeto de los laudos arbitrales, sino que el incumplimiento se produjo porque al verificar que no se solicitó la interpretación dentro de los procesos arbitrales, debió so- 
El TJCA consideró, en los términos que siguen, que los tribunales arbitrales que conocieron de los procesos en Colombia debieron aplicar la normativa andina en materia de interconexión y telecomunicaciones para la resolución de fondo de los procesos y que, para esos efectos, se debía solicitar la interpretación prejudicial de las normas andinas al Tribunal:

"...en el proceso arbitral era necesario y obligatorio la solicitud de la interpretación prejudicial al Tribunal de Justicia de la Comunidad Andina, ya que de lo contrario, existirian operadores jurídicos con funciones judiciales aplicando el derecho comunitario sin contar con la interpretación del Tribunal Comunitario, lo que sin duda alguna afectaría la validez y eficacia del orden supranacional ${ }^{\prime \prime 15}$ (resaltado fuera de texto).

Para justificar esta necesidad y obligatoriedad, el Tribunal hace $-\mathrm{y}$ lo reconoce expresamente-una amplia interpretación del alcance del término "juez nacional" del artículo 33 de la Decisión 472 de la CAN, que es aquel que manda a los "jueces nacionales" a solicitar la interpretación de las normas que conforman el ordenamiento comunitario andino.

Así, el Tribunal considera que el término jurisdicción significa "acción de decidir el derecho", lo cual no solo corresponde a jueces del poder judicial, sino también a aquellos designados por las partes a través de un contrato ${ }^{16}$. Adicionalmente, considera que la potestad de determinar el derecho a través de los procedimientos previstos para el efecto, en el caso de la justicia arbitral, se encuentra en personas con iguales facultades a las que tienen los

licitar al Tribunal se interprete si en el efecto los tribunales arbitrales debian solicitar por su parte interpretación prejudicial y si la falta de dicha interpretación prejudicjal generaria una nulidad procesal por violación al debido proceso. La anterior, el TJCA lo justifica en el doble carácter que poseen los jueces nacionales, como jucces nacionales justamente y tambićn como jueces comunitarios, lo cual ha sido desarrollado por su jurisprudencia en el sentido de que también les corresponde aplicar la normativa comunitaria en sus fallos.

15. Acciỏn de incumplimiento No. 03-Al-2010, p. 31, penúltimo párrafo.

16. Ya en el pasado, el TICA había ampliado cl coneepto de juez nacional a entidades administrativas que pudieran cumplir en los paises micmbros funciones jurisdiccionales y actúen como única o última instancia. Así, en los procesos Nos. 14-IP-2007 y 130-IP-2007 se consideró como jucz nacional a la Superintendencia de Industria y Comercio de Colombia, Grupo de Trabajo de Competencia Desleal. 
jueces ordinarios, salvo por el imperio, y además que los procesos terminan con el laudo arbitral, el cual tiene el efecto de sentencia ejecutoriada y de cosa juzgada, al punto que los jueces nacionales no pueden revisar el fondo de los laudos ${ }^{17}$, sino solo ejecutarlos.

Todo esto lleva a concluir al Tribunal que si los árbitros ejercen funciones jurisdiccionales, para efectos de la norma comunitaria también son jueces nacionales y, por tanto, deben solicitar la interpretación prejudicial al TJCA cuando se trate de laudos en derecho. La solicitud además debe ser directa por parte del tribunal arbitral, sin la necesidad de asistencia judicial ${ }^{18}$.

\section{En palabras del TJCA:}

"Por lo tanto, si los árbitros tienen funciones jurisdiccionales y actúan en última instancia y no dependen de los jueces nacionales; para los efectos de la norma comunitaria actúan como jueces nacionales, es decir, de acuerdo con la interpretación extensiva están

17. En el Ecuador los laudos no son apelables y no cabe contra los mismos otros recursos que los que establece la ley (Art. 31 de la Ley de Arbitraje y Mediación), esto es básicamente los recursos horizontales de aclaración y ampliación.

Adicionalmente a la acción de nulidad -que coma es sabido no constituye propiamente un recurso-, sc ha discutido si contra los laudos caben las acciones extraordinarias de protección constitucionales. Existen colegas del foro que han sostenido que no caben, como es el caso del Dr. Edgar Neira Orellana, quien en su ensayo "La Constitución de 2008 y el arbitraje bajo la ley ecuatoriana: análisis de dos problemas que surgen antes que del texto constinucional, de su cquivocada aplicacion", publicado cn la Revista Ecuatoriana de Arbitraje de 2011, indica en lo sustancial que no cabe estas acciones pues (1) no hay norma que expresamente la contemple para laudos arbitrales, (2) el sistema arbitral es alternativo, (3) la controversia en materia arbitral es de objeto privada y (4) la Asamblea Constituyente de Montecristi climinó del proyecto de Constitución la norma que preveia el control de constitucional de los laudos arbitrales. Sin embargo, lo cierto es que la Corte Constitucional ha venido conociendo acciones extraordinarias de protección presentadas en contra de laudos arbitrales, considerándolas por tanto admisibles sin mayor reflexión ni explicación sobre el tema, aunque tal como se conoce en el medio, no habria aún alguna sentencia de la Corte Constitucional que haya dejacio sin efecto un laudo arbitral.

Por último, el Tribunal pareceria entender que es un principio absolutamente universal del sistema arbitral el que los laudos sean inapelables (ültimo párrafo, p. 34) lo cual si bien es cicrto para los paises que conforman la CAN, que en todo caso es el universo relevante para el Tribunal, no es cierto respecto de los sistemas juridicos de otros paises como es Argentina (ver CAIVANO. Roque J. Arbitraje. Editorial Ad-hoc, 2000, pp. 283 a 288). En todo caso, si a futuro hubiere en cualquier pais de la CAN una reforma legal que permita se revise un laudo por via de apelación (ya sea en sede de un tribunal arbitral o ante la justicia ordinaria), es claro que solo en la última instancia seria obligatorio solicitar la interpretación prejudicial.

18. Considero que fue un acierto del TJCA hacer esta aclaración, pues dilataria innecesariamente el proceso que los tribunales arbitrales tuvieran que acudir a la función judicial para remitir por su intermedio un pedido de interpretación prejudicial al TJCA. 
incluidos dentro del concepto de juez nacional los árbitros que deciden en derecho, luego, deben solicitar la interpretación prejudicial al Tribunal de Justicia de la Comunidad Andina de manera directa, sin que sea necesaria la participación o mediación de organismos judiciales"19 (resaltado fuera de texto).

En el Ecuador, el que los árbitros ejercen funciones jurisdiccionales está reconocido por el propio Código Orgánico de la Función Judicial ${ }^{20}$ en su artículo $7 \mathrm{mo}$, inciso 4 to, lo cual se refiere a la capacidad que tienen de resolver conflictos ("juzgar") y que sus laudos tienen los mismos efectos que los de una sentencia ejecutoriada y de cosa juzgada ${ }^{21}$. Se trata en realidad de una jurisdicción especial, que nace de la convención, está reconocida por la ley, y además es limitada, pues no abarca la capacidad de ejecución de lo resuelto.

Pero el TJCA no se queda allí, sino que además diferencia entre los momentos procesales que pueden existir para solicitar la interpretación prejudicial. Así, indica que se debe distinguir la etapa de decisión del laudo (en la cual se debe solicitar la interpretación prejudicial) de la etapa de ejecución del laudo, la cual como es conocido ya no corresponde a los árbitros en nuestro país, sino a los jueces nacionales. Pues bien, según el TJCA, si a propósito de la ejecución del laudo, el juez de la ejecución encuentra que se debe aplicar normas que conforman el ordenamiento jurídico de la CAN, debe también solicitar la interpretación prejudicial de dichas normas al TJCA ${ }^{22}$.

19. Ibid, p. 34, último párrafo.

20. Registro Oficial 544 Suplemento del 9 de marzo de 2009.

21. Codificación de la Ley de Arbitraje y Mediación. Art. 32, inciso 2do. Registro Oficial 417 del 14 de diciembre de 2006.

22. Acción de Incumplimiento No. 03-Al-2010, p. 35, antepenúltimo parrafo. Esto produciria algo paradójico pues podria ocurrir que un proceso se suspenda antes de dictarse el lauda para que por via de consulta el TICA emita la correspondiente interpretación prejudicial y que después, en la fase de cjecución del laudo, se deba de nuevo suspender el proceso para remitirlo al TJCA por segunda ocasión para que se interpreten otras normas rejacionadas con la cjecución. Es evidente que cslo atentaria contra una de las principales caracteristicas del arbitraje que es la celeridad. 


\section{Consecuencias de la falta de Interpretación Prejudicial}

El TJCA a través de varias sentencias en procesos de interpretación prejudicial, cuyo razonamiento se viene reiterando desde la década de los noventa, ha indicado que la interpretación prejudicial es un presupuesto procesal de la sentencia de obligatorio cumplimiento y que su inobservancia produce una violación al debido proceso y acarrea la nulidad de la sentencia (judicial).

En el proceso No. 10-IP-94 el TJCA indicó:

“La facultad de interpretar las normas comunitarias es una competencia de este Tribunal, por imperio del artículo $28 \mathrm{del}$ Tratado de Creación del mismo... Por mandato de dicho Tratado, los jueces nacionales que conozcan en un proceso de alguna norma comunitaria que deba ser aplicada por ellos en un juicio interno, deben pedir al Tribunal Andino la interpretación de dicha norma conforme lo dispone el artículo 29 de dicho Tratado... la interpretación no es ni puede equipararse a una prueba, sino que constituye tna solemnidad indispensable y necesaria que el juez nacional debe observar obligatoriamente antes de dictar sentencia, la que deberá por otra parte, adoptar dicha interpretación..." ${ }^{23}$ (resaltado fuera de texto).

De otro lado, en el proceso No. 106-IP-2009 el TJCA indicó:

"En el caso de la consulta obligatoria, cuando no cabe un recurso ulterior, el incumplimiento del trámite constituye una clara violación al principio fundamental del debido proceso $y$, en consecuencia, debería acarrear su nulidad, si es que dicha sentencia puede ser materia de un recurso de casación o de un recurso de amparo, toda vez que las normas que garantizan el derecho al debido proceso son de orden público y de ineludible cumplimiento".

Adicionalmente, en el reciente proceso No. 149-IP-2011 (mayo de 2011) el TJCA indicó:

23. En el mismo sentido los procesos Nos. 1-IP-96 y 6-IP-99. 
"Si el juez de única o última instancia ordinaria expide sentencia sin solicitar la interpretación prejudicial, se generan los siguientes efectos: ... La sentencia dictada adolecería de nulidnd. Tal como se mencionó anteriormente, el requisito de la solicitud de interpretación prejudicial, teniendo en cuenta la aplicación inmediata y el efecto directo de la normativa comunitaria andina, entra a formar parte de la normativa procesal nacional de mancra inmediata y automática. Su incumplimiento acarrearía la nulidad de la sentencia y entrarín a ser parte integrante de las causales de nulidad previstas en la normativa interna. Es importante recordar que la violación de las normas procesales es la base para alegar una violación al "derecho al debido proceso". De conformidad con las figuras procesales internas, cualquiern de las partes de un litigio en donde el juez de uinica o última instancia no hubiera solicitado la interpretación prejudicial, podrá alegar la mulidad o invalidez de la sentencia de conformidad con las víns procesales internas: recursos extraordinarios de revisión, casación, etc... La sentencia dictada estaría violando el derecho fundamental del debido proceso. Si la normativa interna lo permite, cualquiern de las partes podrín entablar acciones constitucionales como la tutela, el amparo, la acción de protección, etc."

En el Ecuador existen algunos precedentes de sentencias que han sido casadas por la Ex Corte Suprema de Justicia (hoy Corte Nacional) debido a que se han expedido sentencias por parte de jueces de última instancia ordinaria, sin que se haya suspendido el proceso y requerido al TJCA la interpretación prejudicial respectiva.

Así, por ejemplo, mediante la sentencia expedida en el proceso No. 281-00 del 4 de septiembre de 2002²4, la Sala de lo Contencioso Administrativo de la Ex Corte Suprema de Justicia, casó una sentencia emitida por la Quinta Sala de la Corte Superior de Quito, por falta de aplicación ${ }^{25}$, entre otros, de la norma del Tra-

24. Registro Oficial 22 del 14 de febrero de 2003.

25. En el Ecuador una de las causales por las que se puede interponer un recurso de casación en contra de sentencias o autos que pongan fin a un proceso de conocimiento, es la "Aplicaciön indehida. falta de" aplicacioin o errinea interpretacioin de normas procesales, cuando hayan viciado el proceso de nulidad insanable o prowocato indefension, siempre que hubieren influido en la decisisin de la causa y que la respectiva nulitial no inubiere quctado comvalidada legalmente". 
tado de Creación del Tribunal de Justicia de la Comunidad Andina que mandaba obligatoriamente a suspender el proceso y requerir al Tribunal Interpretación Prejudicial. En su sentencia, la Corte Suprema indicó:

"... Lo anterior nos lleva a la evidente conclusión de que en el caso, al no haberse solicitado el dictamen previo se violó esta disposición comunitaria, la cual en realidad constituye una solemnidad sustancial, su omisión conlleva a la mulidad del proceso. En consecuencia, ADMINISTRANDO JUSTICIA EN NOMBRE DE LA REPÚBLICA Y POR AUTORIDAD DE LA LEY, se declara la nulidad procesal de la presente causa al estado en que dé cumplimiento a la interpretación prejudicial del Tribunal Andino de Justicia de las normas juridicas invocadas ... objeto de la discusión procesal" ${ }^{26}$.

En lo que se refiere a los procesos arbitrales, es conocido que en el Ecuador son procesos de única instancia ${ }^{27}$, por tanto siguiendo la línea de interpretación que se le debe dar al derecho comunitario establecida en la sentencia emitida en la ya comentada acción de incumplimiento No. 03-AI-2011, una falta de interpretación prejudicial solicitada directamente por el tribunal arbitral al TJCA, sería una causal mís de nulidad que se añadiria a las cinco causales que ya constan en el artículo 31 de la Codificación de la Ley de Arbitraje y Mediación ${ }^{28}$. De otro lado, es claro que la nulidad

26. Esto quiere decir que la nulidad procesal produce que el proceso se retrotraiga solo a la etapa anterior a su finalización, pues como ha quedado indicado, el proceso se debe remitir a interpretación prejudicial antes de dictar sentencia. Esto es evidentemente razonable, pues no tendria sentido que la nulidad se extienda a una ctapa anterior del proceso por el principio de economia procesal.

27. Codificación de la Ley de Arbitraje y Mediación, Art. 30. Registro Oficial 417 del 14 de diciembre de 2006.

28. Estoy cn desacuerdo con aquellos que han sostenido que además de las causales que constan en el artículo 31 de la Ley de Arbitraje y Mediación ecuatoriana, son aplicables al proceso arbitral las causales de rulidad de los procesos ordinarios civiles (ver SALCEDO VERDUGA, Ernesto. El A rbitraje Li Justicia Alıemativa. Ed. Distrilib, Guayaquil, 2007, p. 307). Considero que no es necesario acudir al Código de Procedimiento Civil como norma supletoria, cuando el tema de las causales de nulidad de los Jaudos ya cstá previsto expresamente en la propia Ley de Arbitraje y Mediación. Además, esto produciria el sin sentido de que las causales de nulidad del Código de Procedimiento Civil serian aplicables solo a los arbitrajes en derecho y no a los arbitrajes en equidad, siguiendo lo dispuesto por el articulo 37 de la Ley de Arbitraje y Mediación.

En general durante los últimos años, los presidenies de las Cortes Provinciales del pais, particularmente de Pichicha, han entendido que las causales de nulidad de los laudos arbitrales son taxativas y que no cabe declarar la nulidad por algún otro motivo que el accionante reclame pero que no esté previsto en la ley, ni revisar el fondo del laudo. 
no quedaría convalidada ya sea porque en el proceso de ejecución se solicite una interpretación prejudicial o en una acción de nulidad (interpuesta por otra causal), se remita el proceso al TJCA para interpretación.

Lo interpretado por el TJCA en el proceso No. 149-IP-2011 ya citado, respecto de las causales de nulidad de sentencias emitidas por la función judicial, es también perfectamente aplicable para el caso de los laudos arbitrales, pues es el resultado de aplicar los principios de aplicación inmediata y efecto directo de la normativa comunitaria andina.

Esto no quiere decir, por supuesto, que se deban dejar de seguir los lineamientos establecidos por la legislación nacional para intentar la acción de nulidad, tanto en cuanto a requisitos de oportunidad en el tiempo, como autoridad competente para resolverla y trámite aplicable. Se trata, simplemente, de una causal adicional a las establecidas en el artículo 31 de la Ley de Arbitraje y Mediación, que está establecida por vía de una interpretación amplia de las normas comunitarias andinas por el TJCA.

Además de causar la nulidad del laudo arbitral, la falta de interpretación prejudicial causaría un incumplimiento por parte del país miembro por no aplicar las normas comunitarias andi-

Existen, eso si, algunas lamentables decisiones en las que se han aceptado como causales de nuiidad ajgunas no previstas en la ley o se ha entrado directamente a revisar el fondo del laudo. A manera de cjemplo de lo último, puedo citar un alarmante auto, relativamente recienic, emitido por la Corte Provincial de Pichincha, Primera Sala de lo Civil, Mercantil, Inquilinato y Material Residuales el lunes 16 de abril de 2012, en el proceso No. 17111-2010-0894, en donde se afirma lo siguiente: "Si bien en los fallos en cquidad no puede revisarse el lawdo, ya que el criterio de cquidad pertenece en forma exclusiva al arbiam, y en caso de que se dicte un laudo contrario a la equidad solamente cabria que se le exija que repare los daños y perjuicios causados, no es la misma situación que en los casos de laudos en dercho, ya que en ellos el arbitru debe someterse a la ley y: por lo tanto. puede perfectamente revisarse su resolucion y cornegirse cuando aparesa contraria a derecho. Se razona que las partes, al haber pactado la cláusula cumpromisoria, han manifestado st volimad de no someterse a la justicia estatal, perveste argumento que si bien tiene toda rasón en las cusos de arbitraje en cquidal. sin embargo no puede alcanzar a los arbitrajes en derecho, ya que en éstos las partes han expresado su voluntad de someterse al ortenamiento juridico nacional, y es potestad exchusiva del Estado por ser unasunto de onden publico, velar porpue ese ordenamiento juridico nacional no sea transyredido por quienes ejercen dichas potestad jurisdiccional; en el arbitraje en derecho las partes escogen libremente la persona de sit jues, pero no escogen el ondenamiento legal al que se someten, por lo tanto es necesario establecer an órgano que vele por la vigencia de la ley: En tudo caso. la cuestion de ninguna manera es pacifica..." 
nas, lo cual generaría la posibilidad de que dicho país miembro sea sancionado en el marco de la normativa comunitaria (perdiendo privilegios que le otorga el Acuerdo de Cartagena) y además, en el caso de que los afectados sean particulares, el país podría ser demandado para que resarza los daños ocasionados.

Esto llama la atención, pues en el caso de funcionarios públicos, como es el caso de jueces, está bien que el Estado sea responsable por sus omisiones y los perjuicios que ellas causen, pero en el caso de árbitros, se trata de particulares que están envestidos de jurisdicción limitada para un caso particular y eso no los convierte en funcionarios públicos.

Sin embargo, si se considera al árbitro como una persona que actúa en ejercicio de una potestad puiblica (la de administrar justicia), podría entenderse la responsabilidad del Estado con el derecho de repetición en contra del individuo.

A estos efectos, no se puede olvidar que la Constitución de la República del Ecuador en el artículo 11, después de su numeral noveno, establece que el Estado, su delegatarios, concesionarios y toda persona que actúe en ejercicio de una potestad pública tiene la obligación de reparar violaciones a los derechos de los particulares por la falta o deficiencia en la prestación de los servicios públicos y que el Estado ejercerá de forma inmediata el derecho de repetición en contra de las personas responsables del daño producido.

\section{El Consejo de estado de Colombia y cómo REACCIONÓ FRENTE A LO DISPUESTO EN LA ACCIÓN DE INCUMPLIMIENTO NO. 03-AI-2010}

El incumplimiento que se produce por la falta de interpretación prejudicial de aquellas normas que debían aplicarse al proceso arbitral, como ya se explicó antes, no solo desemboca en una declaratoria de incumplimiento del país correspondiente y en un 
posible reclamo de indemnización por parte del particular afectado, sino que el país miembro mantiene además la obligación de adoptar las medidas que sean necesarias para efectivamente dar cumplimiento a la normativa andina ${ }^{29}$.

Después de que la República de Colombia fue notificada con la resolución proferida en la acción de incumplimiento tantas veces comentada, solicitó su enmienda en determinadas partes y en subsidio su aclaración, pues consideraba que en la misma no se precisaba con claridad en qué consistía el proceder con el que debía cumplir el Estado para dar cumplimiento a la resolución.

El TJCA resolvió ambos pedidos el 15 de noviembre de 2011, indicando que no había lugar a las enmiendas solicitadas, pero si a la aclaración, en especial en lo referente a las acciones que debía adelantar el Consejo de Estado de la República de Colombia. Entre otros, se le dispuso lo siguiente:

“- De conformidad con las previsiones del derecho procesal interno colombiano, dejar sin efecto las providencias que resolvieron los recursos de anulación.

- Es decir, en este momento la obligación que tiene el Consejo de Estado es dejar sin efecto las providencias que resolvieron los recursos de anulación y aplicar la Sentencia de 26 de agosto de $2011 \ldots$

- Que, finalmente, de acuerdo al artículo 111 del Estatuto del Tribunal, el País Miembro que incumplió una norma comunitaria quedará obligado dentro de los noventa (90) días siguientes a la notificación de la Sentencia a adoptar las medidas que estime convenientes para dar cabal cumplimiento a la Sentencia, descrita en el presente auto".

29. Codificación đócl Tratado de Creación del Tribunal de Justicia de la Comunidad Andina (Decisión 472). Art. 27, concordante con el Art. 111 del Estatuto del Tribunal de Justicia de la Comunidad Andina (Decisión 500). 
Así, el Consejo de Estado, no en noventa días, pero sí varios meses después, terminó dando cumplimiento al pronunciamiento del TJCA a través de sentencias similares emitidas el 9 de agosto de 2012, en las cuales reconociendo en la situación de dificultad en que se encontraba, pues "dentro del ordenamiento jurídico colombiano no existe un procedimiento específico, claro y debidamente detallado que determine la manera en que deben cumplirse las decisiones adoptadas por el Tribunal de Justicia de la Comunidad Andina, concretamente por cuanto respecta a aquellas que le impongan al Estado Colombiano -y, en especial, al Consejo de Estado de la República de Colombia-la obligación de adelantar 'acciones' encaminadas a cumplir tales decisiones..." ${ }^{130}$, dejó sin efectos sus propias sentencias mediante las cuales había declarado infundadas las peticiones de nulidad de los laudos arbitrales (aquellas sentencias que dieron origen a la acción de incumplimiento) y además declaró la nulidad de los laudos arbitrales correspondientes.

El Consejo de Estado de Colombia terminó ejerciendo competencia como Juez Comunitario, considerando que en la lista taxativa de causales entre las cuales puede sustentarse la nulidad de un laudo arbitral, también se encuentra la omisión del deber de solicitar interpretación prejudicial de normas comunitarias andinas y que en base a los principios de aplicación inmediata, efecto directo y primacía de las normas comunitarias andinas, cumpliendo con lo que le dispuso el TJCA, estaba en capacidad y lo que es más obligado tanto a dejar sin efecto sus sentencias previas, como a declarar nulos los laudos que generaron la declaración de incumplimiento de la República de Colombia.

\section{Conclusiones}

La expresamente amplia interpretación que el TJCA ha realizado del concepto de "juez nacional" del artículo 33 de su Tratado de Creación, engloba sin duda a los árbitros en derecho.

30. Sentencia cmitida el 9 de agosto de $\mathbf{2 0 1 2}$ por el Conscjo de Estado, Sala de lo Contencioso Administrativo. Sección Tercera - Sala Plena, acapite II Consideraciones, numeral 3ero. 
Con la antedicha interpretación se ha creado una causal adicional para la nulidad de los laudos arbitrales, cuando el proceso arbitral de única instancia no ha sido suspendido para solicitar de manera previa a dictar el laudo, ya sea de oficio o a petición de parte, la interpretación prejudicial de normas comunitarias que sean aplicables al caso ${ }^{31}$.

La falta de remisión de un proceso para la interpretación prejudicial correspondiente, no solo que pondría en riesgo la validez del laudo arbitral que se emita, sino que además podría sujetar al país miembro en cuyo territorio se emitió el laudo, a ser declarado incumplidor de la normativa andina por el TJCA y eventualmente, si no se subsana a tiempo el incumplimiento, a ser sancionado a través de medidas que lo afectarían comercialmente en la región andina.

31. Considero que la remisión del proceso al TJCA para interpretación prejudicial cn nada afecta al término máximo de duración del arbitraje de 150 dias que establece el artículo 25 de la Codificación de la Ley de Arbitraje y Mediación del Ecuador, cxtraordinariamente prorrogable por un periodo igual, pues cl proceso quedará suspendido - sin que corran términos- desde el momento en que se solicite la interpretación prejudicial hasta el momento en que el TJCA la remita al Tribunal Arbitral. 